\title{
As Repercussões do Cuidado na Vida do Cuidador Familiar do Idoso com Demência de Alzheimer'
}

\author{
Repercussions of Care in the Life of Family Caregivers of \\ Elderlies with Alzheimer's Disease
}

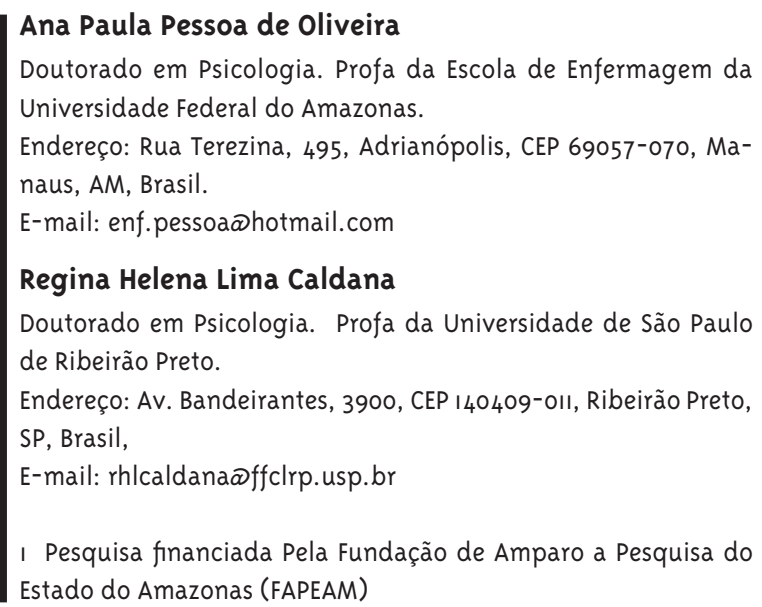

\section{Resumo}

Nos últimos anos tem aumentado progressivamente o número de famílias que se tem confrontado com a situação de cuidar de familiares idosos em condição de dependência, principalmente quando esta é provocada em virtude da Doença de Alzheimer (DA). O objetivo deste estudo é o de investigar as repercussões do cuidado na vida do cuidador familiar de idoso com demência de Alzheimer. Através da epistemologia qualitativa utilizou-se a técnica da entrevista na modalidade de história de vida temática aplicada a vinte cuidadores de idosos cadastrados na Associação Brasileira de Alzheimer do estado do Amazonas (ABRAZ-AM). Os resultados mostraram que as renúncias aparecem nos depoimentos dos familiares como uma repercussão significativa do cuidado. A privação social em função do cuidado é uma realidade presente na vida dos cuidadores deste estudo. A raiva, a impaciência, o medo, a solidão e a vergonha são sentimentos vivenciados pelos cuidadores em seu cotidiano, que se alternam com sentimentos de satisfação, felicidade, compaixão e de retribuição. É importante salientar que neste estudo, a situação de cuidado vivenciada pelos cuidadores é permeada por sentimentos que se contrapõem, em determinados momentos se configurando como desagradáveis e em outros momentos como agradáveis. Sendo assim, percebe-se que é possível e relevante os profissionais da saúde identificarem esses aspectos favorecedores de prazer na relação de cuidado, buscando exaltálos perante os outros. Dessa forma, a possibilidade de enfrentar da melhor forma os percalços deve ser considerada uma realidade eminentemente presente no cotidiano de cuidado.

Palavras-chave: Cuidado familiar; Idoso; Alzheimer. 


\section{Abstract}

In recent years there has been a progressive increase in the number of families confronted with the situation of caring for elderly relatives in a dependent condition, principally as a result of Alzheimer's disease. The objective of the present study was to investigate the repercussions of such care in the life of family caregivers of elderly relatives with Alzheimer's disease. By means of qualitative epistemology, the interview technique was used in the thematic life history modality, and applied to 20 caregivers of elderly individuals enrolled in the Brazilian Association of Alzheimer's Disease in the State of Amazonas, Northern Brazil. The results showed that renouncements emerge in the caregivers' testimonies as a significant repercussion of care. Social deprivation is a reality that is present in the lives of all the caregivers who took part in this study. Anger, impatience, fear, loneliness and shame are feelings experienced by the caregivers in their everyday lives, intermingling with feelings of satisfaction, happiness, compassion and retribution. It is important to highlight that in the present study the care situation lived by the caregivers was permeated by opposing feelings, being considered unpleasant in certain moments and pleasant in others. Thus, it is perceived that it is possible and relevant for the health professionals to identify the pleasurepromoting aspects in the care relationship, praising them before the others. Therefore, the possibility of facing the mishaps in the best possible way should be considered as an eminently present reality in the daily routine of care.

Keywords: Family Care; Elderly; Alzheimer.

\section{Introdução}

Nos últimos anos tem aumentado progressivamente o número de famílias que se tem confrontado com a situação de cuidar de familiares idosos em condição de dependência, principalmente quando essa é provocada por processo demencial em virtude da Doença de Alzheimer (DA). Esses idosos e seus familiares carecem de uma rede de apoio para permanecerem inseridos socialmente (Oliveira, 2009).

Pavarini e colaboradores (2008) realizaram estudos no interior de São Paulo com cuidadores familiares de idosos com DA e concluíram que o cuidado vivenciado pelos familiares é uma experiência muito pessoal, depende da fase da doença, da qualidade da rede de suporte familiar, da vida de cada família e da forma como cada família enfrenta esta situação.

Assim, a demência de Alzheimer muda significativamente o cotidiano das famílias. Por apresentar uma evolução extremamente personalizada e produzir um quadro insidioso, progressivo e crônico, com grande repercussão emocional e socioeconômica sobre as famílias, as demandas físicas, emocionais e sociais podem tornar alguns membros da família exaustos, deprimidos e estressados, especialmente aqueles que assumem com maior intensidade a função de cuidador, com consequências sobre a sua saúde física e mental (Caldeira e Ribeiro, 2004).

Em função da relação com o idoso antes do processo demencial, esse cuidador possivelmente tem dificuldade de aceitar as mudanças do portador da demência que progressivamente vai assumindo outro modo de ser, embora conserve a mesma aparência física, bastante conhecida. 0 cuidador pode ainda se deparar com situações conflitantes no cotidiano com a pessoa de quem cuida. Assim, proporcionar cuidados ininterruptos ao idoso demenciado pode ocasionar inúmeras demandas aos cuidadores, representando-lhes um ônus que precisa ser compartilhado com outras pessoas (Oliveira, 2009).

o cuidado dispensado ao idoso doente torna-se muito complexo, pois a família se percebe envolvida em sentimentos difíceis de manejar, que acabam por lhes impor certo isolamento nas atividades do cuidado, abalando profundamente os sistemas emocionais, acarretando em privações e modificações no estilo de vida para incluir as novas necessidades de seu membro doente. 
Segundo Santos (2003), a doença extrapola o evento biológico em si, pois é uma construção sociocultural que possui diferentes significados e interpretações de acordo com quem vivencia e suas relações interpessoais, principalmente dentro da família.

A família que possui idoso com alta dependência em função do processo demencial está sujeita a uma constante carga de tensão, podendo seus membros tornar-se exaustos, desgastados física e emocionalmente, ao mesmo tempo em que pode haver desestruturação financeira de um modo geral. Assim, cuidar de um idoso portador de Demência de Alzheimer pode ser uma das tarefas mais complicadas para a família. Pesquisa (Almberg e col., 1997) sinalizou para o alto nível de estresse entre os cuidadores.

No contexto familiar, a pessoa que assume o papel de cuidador está sujeita a produção de demandas de cuidados que afetam sua dimensão física, mental e social (Luzardo e col., 2006). Particularmente, a dependência psicofuncional do idoso com demência, ao modificar a rotina, a dinâmica e a relação de troca entre os membros da família, pela inversão de papeis, coloca uma série de demandas novas e inesperadas, que podem ser angustiantes para quem cuida, em virtude de envolvimento afetivo entre o idoso e família. Essa angústia pode levar o cuidador familiar a vivenciar momentos de ansiedade em seu dia a dia. Toda essa movimentação emocional do cuidador familiar leva o idoso com doença de Alzheimer a uma labilidade afetiva, ou seja, a uma instabilidade das relações afetivas, o que também se atribui à insuficiência da regulação interna dos afetos (Goldfarb, 1996). O cuidador tem de superar muitos desafios para exercer com precisão seu papel (Caldeira e Ribeiro, 2004).

Dessa maneira, a demência de Alzheimer é reconhecida, a exemplo de outras demências, como um importante problema de saúde pública em todo o mundo.

Estabeleceu-se como objetivo do presente artigo investigar as repercussões do cuidado na vida do cuidador familiar de idoso com demência de Alzheimer, por entender que a família do idoso doente não deve ser considerada somente como uma unidade de cuidado, mas também como uma unidade a ser cuidada. A partir dos achados da pesquisa, pretende-se contribuir para a promoção da saúde de familiares cuidadores.

\section{Metodologia}

O presente estudo é parte de uma pesquisa de maior amplitude (Oliveira, 2009) cujo objetivo foi compreender, a partir da perspectiva de cuidadores familiares de idosos com diagnóstico de demência de Alzheimer, a situação de cuidado familiar em suas diferentes dimensões, à luz da história de vida dos cuidadores.

Através da epistemologia qualitativa este estudo busca valorizar a história e o contexto dos cuidadores, que são sujeitos marcados pela sua individualidade na relação de cuidado ao idoso com Alzheimer. Esta abordagem procura enfatizar as construções sociais da realidade, pautando-se no caráter interativo entre o pesquisador e o pesquisado, em que se constitui um processo que facilita a expressão de ideias e emoções que só surgem ao calor da reflexão conjunta e espontânea no momento do contato entre ambos (Caldana, 1998; Tozo, 2002; Pegoraro, 2007).

O estudo teve início após a aprovação do projeto pelo Comitê de Ética em Pesquisa da Universidade Federal do Amazonas (UFAM), CAA n. 0281.0.115.0ooo7. Foi utilizado o Termo de Consentimento Livre e Esclarecido no momento da realização das entrevistas e, como forma de garantir o sigilo quanto à identificação dos participantes, seus nomes foram alterados.

Para buscar a compreensão do cuidado no contexto das experiências vividas, optou-se pela busca da história de vida dos cuidadores familiares. A determinação por esse caminho privilegia a expressão do vivido, focalizando experiências individuais e coletivas de relacionamentos e aprendizado na convivência familiar, o que inclui toda forma explícita ou implícita de perspectivas e sentimentos que poderão se apresentar diretamente ou nas entrelinhas dos depoimentos.

A técnica utilizada para a obtenção dos depoimentos dos participantes deste estudo foi a entrevista que, segundo Biasoli-Alves e Dias da Silva (1992), é uma ferramenta imprescindível para contextualizar o comportamento dos sujeitos, vinculando-a aos sentimentos, crenças, valores, permitindo que se obtenham dados sobre o passado recente ou longínquo. 
Assim, na modalidade de história de vida temática, os detalhes da história pessoal do entrevistado interessam na medida em que podem ser úteis ao objeto do estudo, auxiliando na aquisição de detalhes procurados. Nesse sentido essa foi a estratégia escolhida: para melhor compreender a situação do se tornar cuidador de idoso com demência de Alzheimer, acredita-se ser necessário buscar o significado das suas próprias vivências dentro da história de sua vida.

O processo de análise deste estudo seguiu os momentos, enfatizados por pesquisadores que trabalham com este tipo de abordagem (André, 1988; Biasoli-Alves, 1995): execução das entrevistas e registro literal dos dados; transcrição literal das entrevistas gravadas; leituras sucessivas das entrevistas transcritas; sistematização dos dados coletados pela procura de regularidade e diferenças nas respostas dos participantes e delimitação progressiva do foco de estudo, seguindo-se o afunilamento dos resultados em função do referencial conceitual; eleição de tópicos e temas, tendo como aporte a literatura e as próprias verbalizações dos participantes, buscando redigir com coerência e fluidez, encaminhando o leitor para compreensão e crítica do texto.

O presente artigo propõe-se a discutir parte do material referente ao tema central "O cuidado no momento atual”, especificamente a unidade temática "Repercussões na vida do cuidador".

Foram entrevistados vinte cuidadores familiares cadastrados na ABRAZ-AM na cidade de Manaus. 0 objetivo dessa organização é propor à comunidade amazonense a formalização e consolidação de um grupo de apoio no intuito de congregar famílias, cuidadores e profissionais, dando informações sobre a doença, com o objetivo de melhorar as condições de vida do idoso acometido pela demência de Alzheimer e de seus familiares.

Os critérios utilizados para a seleção dos participantes foram: estar cuidando do idoso há pelo menos cinco meses, por considerar-se que com este tempo há uma convivência a ser historiada; ter apresentado disponibilidade para fornecer entrevista longa, gravada, mediante sigilo de identificação; ser responsável pelo cuidado do idoso, não recebendo nenhum tipo de remuneração.

\section{Apresentação e Discussão dos Resultados}

A faixa etária do grupo de cuidadores entrevistados mostrou-se bastante ampla, dos 26 aos 82 anos, com maior concentração entre 40 e 60 anos. É interessante apontar que no caso de sete deles, com idade igual ou superior a 60 anos, são idosos, se tem um idoso cuidando de outro idoso. É importante salientar que, nesse caso, o idoso que assume a responsabilidade pelo cuidado de outra pessoa idosa também se encontra numa situação possível de ser cuidado, em função de apresentar algumas limitações físicas provenientes do processo de envelhecimento, bem como da instalação de doenças crônicas nãotransmissíveis.

Na sua quase totalidade são mulheres, responsáveis pelo cuidado, sendo apenas três homens. 0 grau de parentesco entre o cuidador e o idoso sob seus cuidados é de filiação: em sua maioria, filhas que cuidam dos pais. Há também dois netos, uma mulher e um homem, cuidando de avós que foram responsáveis pela criação de ambos, assim possuem uma relação de filiação com as avós, considerandoas como mães.

Das mulheres, a grande maioria é casada e coabita com os filhos, que ainda não saíram de casa por serem crianças, adolescentes ou estarem na idade adulta e ainda não terem se casado. 0 nível de escolaridade do grupo de entrevistados é alto; todos têm no mínimo o nível médio.

A maioria dos idosos sob cuidados é composta por viúvos há mais ou menos 10 anos, na sua totalidade, apresentam alterações na memória, muitos deles não se lembram do cuidador como membro da sua família, principalmente quando este é seu filho ou filha. No entanto, estes idosos têm estas cuidadoras como referência no dia a dia do cuidado.

As renúncias aparecem como uma repercussão significativa do cuidado em sua vida atual. 0 cuidador tem a clara percepção do que deixou e deixa de fazer na sua vida particular, profissional e social em função do cuidado ao idoso.

Para alguns cuidadores, a responsabilidade pelo cuidado os impede de casar e construir a sua própria família, como é o caso do Sr. Francisco que está noivo. Já para outros, põe em risco o casamento pela 
perda da privacidade do casal pelo fato do idoso sob cuidado dormir no mesmo quarto e em um dos casos no meio da cama, proporcionando a perda do contato físico noturno entre marido e mulher:

Ela [mãe] dormi entre eu e meu marido... (Graça, 57 anos )

a mamãe dorme comigo e meu marido, no nosso quarto... (Valdete, 58 anos)

A mudança de planos em relação ao seguimento profissional faz parte também do quadro de renúncia dos filhos que cuidam de seus pais. A limitação profissional se faz presente, no caso de Alma, pelo fato de ter que trabalhar em casa para não se afastar da mãe, adaptou seu laboratório em um dos compartimentos do seu domicílio; tendo que trabalhar mediante a rotina do cuidado, limitando-se a aceitar encomendas somente pela parte da tarde, horário em que a idosa está mais tranquila:

Eu trabalho num... geralmente assim, quando eu marco, é pela parte da tarde, pra eu trabalhar, sabe? Mas quando eu vejo que a situação tá muito pesada eu desmarco, porque tudo eu faço com hora marcada né?! eu faço meus trabalhinhos com hora marcada, de repente a mamãe muda completamente, aí eu não posso. Então, eu sinceramente, gostaria até de trabalhar fora porque eu fico fazendo meu trabaIhinho ali no meu laboratoriozinho, eu tô ali mas o que tá acontecendo aqui vem um e me fala, aí eu já fico agoniada. Então, eu gostaria de trabalhar fora, fazer um trabalhinho fora, num horário, sei lá, não sei quantas horas, ficar fora e depois chegar em casa entendeu?! [...] coloquei meu laboratório lá num compartimento dentro da minha casa mesmo... (Alma, 53 anos)

Houve inclusive um caso em que a cuidadora escolheu seguir uma profissão relacionada à área da saúde para buscar conhecimentos acerca de como cuidar da sua mãe, fato este que possibilitou, por alguns anos, o atraso no andamento da faculdade de outra área que ela estava cursando:

Fiz o curso de técnica de enfermagem para cuidar da minha mãe, a gente tem que saber sobre essa doença e como cuidar, né?!..( Fernanda, 32 anos)

A privação social em função do cuidado é uma realidade presente na vida dos cuidadores deste estudo. Deixar de sair com os amigos, de participar de reuniões familiares e de viajar faz parte do cotidiano dessas pessoas, que se enclausuram nas tarefas e sentimentos que permeiam o cuidar. 0 lúdico não consegue ganhar espaço para amenizar os efeitos desagradáveis sobre o cuidador no dia a dia do cuidado:

Eu iria viajar e minhas irmãs que cuidam dele comigo resolveram viajar também, abri mão da minha viagem para que elas fossem, me sinto muito sobrecarregada, das três sou eu que tenho mais responsabilidade com o papai... (Margareth, 6o anos)

Às vezes não saio, porque não posso levá-la, quando vou a um aniversário que a levo, meus irmãos reclamam comigo porque a levei, pois ela dá muito trabalho... (Jéssica, 46 anos)

[...] Eu teria que fazer como fiz, muitas renúncias na minha vida. Porque eu gosto de jogar minha bola, tá entendendo? Renunciei... (Francisco, 51 anos)

Eu abdico de muita coisa por estar cuidando dela, eu e meu marido não podemos sair juntos, viajar juntos, ou vai um ou o outro... (Eliane, 66 anos)

O "viver para cuidar" é uma realidade demonstrada nas entrelinhas dos depoimentos do cuidador, em que a sua vida passou a ser a vida do idoso sob cuidado. A doação pelo cuidado, na visão do cuidador, impede o atendimento das suas necessidades psicossociais, tornando-o, em alguns momentos, pessoas inseguras por se sentirem anuladas:

Eu vivo para ela [mãe], me anulo em meus pensamentos, em meus sonhos por causa do cuidado dela... (Alma, 53 anos)

O depoimento de Alma parece mostrar um sentimento, frente ao cuidado, de insatisfação diante da situação, por não poder concretizar os seus sonhos. Alma, ao enfatizar a expressão "por causa do cuidado dela" parece atribuir à mãe culpa pelos momentos vivenciados. Culpa esta proveniente de uma história de sofrimento e passividade durante a convivência matrimonial.

Outra repercussão significativa do cuidado que se configura nas falas do cuidadores diz respeito aos sentimentos vivenciados em cada momento de seu dia a dia. Sentimentos que se alternam e se pareiam frente às situações vivenciadas. A raiva 
é um sentimento experienciado no cotidiano do cuidado, em virtude da não aceitação da doença no cônjuge, doença esta que impõe um cuidado que a mantém prisioneira, ocasionando abdicações da sua própria vida em função do idoso doente. Essa raiva da situação pela qual a idosa se encontra ao cuidar do cônjuge gera momentos de impaciência no manejo do cuidado, conforme trecho da entrevista:

No dia a dia, o meu filho me pede muito para ter paciência com o Zé [marido], mas já estou com a minha esgotada, todo dia é a mesma coisa. Tem horas que me dá raiva dessa situação, dessa doença, de tudo [pausa] quando estamos sozinhos tenho que ficar o tempo todo atrás dele com medo dele fazer uma bobagem [...] É difícil a situação [...] é muito trabalho, muito trabalho, muito trabalho mesmo. Deixei de viver para viver a vida dele, e que vida... (Izolda, 75 anos)

A impaciência é um sentimento que aparece na quase totalidade dos entrevistados. 0 cuidador se sente impotente diante da doença no idoso quando vivencia situações não facilmente conduzidas nas tarefas do cuidado. Os momentos de impaciência causam tristeza no cuidador pelo arrependimento de não ter tido a capacidade de suportar os comportamentos inadequados do idoso sob cuidado:

[...] Ela esta começando a ficar agressiva na hora de tomar banho, machuca agente, tem horas que peço ajuda a Deus, pois às vezes perco a paciência e isso me entristece... (Jéssica, 46 anos)

O medo é uma constância na vida de alguns cuidadores. Cada demonstração de dependência de cuidados pelo idoso doente traz para o cuidador o imenso desejo de não ficar nesta mesma situação, o medo de um dia ser acometido por qualquer doença que o faça perder sua capacidade funcional; que o torne eterno dependente dos cuidados dos outros:

[...] tenho muito medo de um dia esta doença me pegar, não quero ter que ficar assim, dependendo dos cuidados dos outros, sem poder fazer aquilo que eu quero [...] Deus me livre! ( Ângela, 42 anos)

[...] ter que precisar de alguém para levar ao banheiro, para tomar banho, para vestir a roupa, para poder comer [pausa] isso é muito triste, eu não quero ficar assim, tenho muito medo... (Alma, 53 anos)
O sentimento de medo é experienciado também por uma das idosas que cuida do cônjuge na fase inicial da doença, medo este da perda total de memória do marido, fazendo-o esquecer do casamento e da mulher que tanto o ama. Em função do medo, a cuidadora se mantém todo o tempo ao lado do seu marido para que a sua presença seja marcante a todo o momento:

Eu tenho muito medo de que ele esqueça, se esqueça de mim, não quero que isso aconteça, vai ser muito triste pra eu ter que suportar [...] ele não pode esquecer a mulher que lhe ama tanto, por isso fico o tempo todo com ele para que não me esqueça[pausa] ele anda grudado o tempo todo em mim... (Rosângela, 64 anos)

A solidão é um sentimento vivenciado pelas esposas que cuidam do marido. O companheirismo, com o surgimento da doença, foi perdido em virtude dos maridos não lembrarem, em alguns momentos, que são casados e nem as reconhecerem como mulheres. Assim, as idosas sentem que perderam para o Alzheimer o companheirismo constante do seu esposo, cumplicidade mútua que perdurou por vários anos e que atualmente se sentem sozinhas, sem poder compartilhar com o idoso os sentimentos vivenciados no dia a dia:

Ele [marido] sempre foi meu companheiro, mas agora eu me sinto só pausa] eu não posso mais dividir tudo com ele. [...] sito muita falta da cumplicidade que tínhamos um com o outro, nós sempre contávamos tudo, sem medo... (Rosângela, 64 anos)

Queria muito ter meu companheiro de volta [pausa] agora ele [marido] fala coisa com coisa, às vezes se esquece de mim, fico muito sozinha (Almerinda, 78 anos)

Outro tipo de solidão mencionado pelos cuidadores que não recebem ajuda da família no cuidado do idoso foi a solidão da atividade, ou melhor, o estar só no desempenho e na responsabilidade do cotidiano do cuidar, conforme as falas a seguir:

[...] eu sempre estou só, sou eu para tudo, ninguém me ajuda em nada [...] (Margareth, 6o anos)

Eles [irmãos] não me ajudam em nada, eu estou o tempo todo sozinha no dia a dia com o papai... (Alma, 53 anos) 
Só eu que assumo sempre tudo com ela [avó]... (Jorge, 36 anos)

Outro sentimento relatado pelas cuidadoras, principalmente pelas esposas dos idosos sob cuidados, é o de vergonha, proporcionando assim, o afastamento do convívio social. É situação particularmente constrangedora para a cuidadora ver seu marido não usar adequadamente o banheiro para as suas necessidades fisiológicas, abordar pessoas desconhecidas na rua, ter crises de ciúmes sem motivos e não se lembrar da cuidadora como sua mulher. Conforme demonstrado nas falas da dona Izolda e dona Almerinda:

[...] evito de sair com ele [marido], não vou mais a igreja [...] ele não tem mais noção das coisas, não usa direito o banheiro, tira a calça em qualquer lugar e faz xixi, eu morro de vergonha [...] fica no portão de casa chamando as pessoas que conhece, sabe?[...] me dar muita vergonha quando ele fala na frente das pessoas que não sou sua mulher (Izolda, 75 anos)

[...] fico com muita vergonha dele [marido], do nada ele faz crise de ciúmes, fica desconfiando de mim, diz que tenho um amante, prefiro não sair [...] (Almerinda, 78 anos)

A compaixão é um sentimento que aparece nos relatos dos cuidadores. Sofrer pelo sofrimento do idoso, na visão do cuidador, é uma realidade vivenciada no dia a dia frente ao cuidado.

[...] sofro muito quando a vejo [mãe] sofrendo em cima daquela cama, naquela situação... (Alma, 53 anos)

Todo dia fico pensando no quanto que ela [mãe] sofre por vivenciar uma situação desta... (Carlos, 43 anos)

Compartilhar o sofrimento parece ser uma grande demonstração de preocupação e amor de filho, no intuito de buscar amenizar tal situação vivenciada pela idosa. Os cuidadores investem no cuidado protegido e abnegado.

Um sentimento expressado também pelos cuidadores foi o de felicidade, por poder ter forças e condições de cuidar da sua mãe e do seu pai que se encontram doentes. A satisfação de poder retribuir aos pais o cuidado dispensado por toda a vida im- pulsiona esses filhos a investirem a todo custo no bem-estar daqueles que tanto amam e admiram:

[...] sou feliz em poder cuidar do meu pai, sou feliz, amo meu pai, amo minha mãe e amo a vida. ( Francisco, 51anos)

[...] me sinto feliz em poder cuidar da minha mãe, apesar de tudo que estou passando, ela é a pessoa que sempre cuidou de mim e agora é minha vez de cuidar dela, graças a Deus, ela melhorou bastante com os meus cuidados... (Valdete, 58 anos)

Os sentimentos frente ao processo do cuidado aparecem, neste estudo, relacionados ao senso de realização, a sentimentos de felicidade, amor, satisfação, retribuição, a dar exemplo de solidariedade aos filhos e, de força, senso de responsabilidade social pela satisfação em cumprir o seu papel enquanto filho, responsabilidade pelo cuidado, bem como o sentimento de cumprir o dever cristão. A literatura traz diversos sentimentos positivos frente à tarefa do cuidado, como o de gratidão, de prazer, de alegria, melhora no senso de realização, o de dar continuidade à tradição familiar, sentir-se bem com a qualidade do cuidado oferecido (Kramer, 1997; Sommerhalder e Néri, 2002). Noonan e Tennstedt (1997) demonstraram que o significado positivo na tarefa de cuidar aumenta o bem-estar psicológico do cuidador.

Nesta pesquisa, a maioria dos filhos que cuidam dos pais refere estar retribuindo o cuidado recebido por estes, ao longo da sua vida, fato que lhes traz sentimento de satisfação por tal oportunidade. A família compreende que prestar cuidado ao idoso é sua obrigação, uma vez que em momentos anteriores da vida o idoso estava na posição de cuidador. Assim, agora ocorre a inversão de papeis entre gerações como uma forma de retribuir a dedicação de tempo e cuidado. Em seu estudo Alvarez (2001) também observa que as famílias que cuidam de seu familiar idoso identificam isso como o cumprimento do dever moral. Conforme Sommerhalder (2001), para os cuidadores, o senso de reciprocidade e a possibilidade de retribuição estavam relacionados ao senso de crescimento pessoal e ao senso de autorrealização, trazendo-lhes o aumento do significado da vida, prazer e satisfação própria. Néri e Carvalho (2002) apontaram pesquisas nas quais os cuidadores afir- 
maram que a atividade de cuidar traz para eles o senso de utilidade, significação existencial, pessoal e de reciprocidade sendo, portanto, vista como algo positivo.

A obrigação moral de cuidar, o sentimento de solidariedade, o amor e a motivação para retribuir experiências gratificantes de cuidado se fazem presentes na situação de cuidado deste estudo, corroborando com os achados apontados no estudo de (Perracini e Neri, 2006). O cuidado para os cuidadores é visto como uma forma de retorno do cuidado recebido pelos pais ao longo da sua vida, constituindo-se em um fator determinante para o comprometimento do cuidado, no presente ou em um futuro próximo (Mazza e Lefèvre, 2005).

A obrigação de cuidar do idoso doente em função do cumprimento do papel social enquanto filho (a), neto (a) e esposa pode ser um dos fatores estressantes que o cuidador vivencia no processo de cuidado. Uma vez que no estudo de Meira e colaboradores (2007), o estresse significa pressão, em que o cumprimento do dever social exerce uma pressão no cuidador frente à perspectiva de cuidado do familiar idoso. Pode-se dizer que os cuidadores deste estudo vivenciam situações de estresse pela pressão do estado de constante vigília, atenção e preocupação para com o idoso, gerando momentos difíceis em suas vidas.

Para Teixeira (1998), a situação de estresse ocasionada pelo cuidar, que pode ter uma variabilidade de intensidade no mesmo cuidador ao longo do tempo, também pode produzir prazer e conforto quando o mesmo se envolve em suas tarefas e consegue perceber resultados positivos, independentemente da exigência dos esforços físicos e psíquicos do dia a dia do cuidado. Neste estudo os resultados positivos aparecem ligados à oportunidade de retribuir o cuidado que receberam já mencionados anteriormente, como acontece com os filhos e netos dos idosos doentes.

Vieira (2004) enfatiza que, mesmo que o ato de cuidar se torne prazeroso, a situação gera ansiedade e angústia, pois coloca em segundo plano os interesses e necessidades de quem cuida o que compromete a qualidade do cuidado oferecido.

Os efeitos negativos relacionados à tarefa do cuidar estavam associados a ressentimento, tris- teza, impaciência, cansaço, pesar pela condição do idoso, sobrecarga por acúmulo de funções, falta de privacidade e problemas familiares gerados pelas dificuldades de aceitação em relação à doença do idoso. Esses resultados corroboram com outros estudos (Sommerhalder e Neri, 2002; Karsch, 2006).

A sobrecarga de tarefas impostas ao cuidador deste estudo gera impossibilidade do mesmo participar de relações sociais, contribuindo com a pesquisa realizada por Nardi e Oliveira (2008) com cuidadores familiares de idosos dependentes no município de Jandaia do Sul no estado do Paraná.

Os efeitos negativos da sobrecarga a que os cuidadores deste estudo estão expostos não podem ser ignorados, mas também não se pode negar que a experiência do cuidado também traz crescimento pessoal para filhos, netos e cunhados. Perracini e Néri (2006) trazem que o julgamento que os cuidadores trazem das tarefas de cuidar é afetado por fatores pessoais, pelo grau de parentesco com o idoso e sua personalidade, bem como pelos valores e crenças do cuidador.

A sobrecarga devido à função de cuidador único e no tempo prolongado de cuidados, a imposição da função de cuidador na família, o acúmulo de fatores estressantes e o comportamento adverso do idoso sob cuidado, no estudo de Meira e colaboradores (2007), são os fatores potenciais de violência familiar.

A perda da paciência se faz presente no cotidiano do cuidado pelo cuidador, em virtude das limitações, da repetição de erros e agressividade do idoso doente. Nessas situações, pôde-se constatar que foram comuns os cuidadores, deste estudo, referir ficar com raiva ou até vontade de agredir o idoso doente, mas logo em seguida estes cuidadores foram tomados por um forte sentimento de culpa em virtude de perceber que não deveriam ter perdido a paciência com seu ente tão querido. Esses sentimentos que permeiam o cuidador no dia a dia do cuidado também foram encontrados na pesquisa de Santos (2003).

A frustração foi uma constante nos discursos das idosas, que exercem o papel de cuidadora de seu marido, uma vez que a doença do parceiro fez com que os projetos de vida, almejados por ambos para a velhice, se tornassem irrealizáveis. Dessa forma, essas idosas perceberam que perderam o compa- 
nheiro com o qual compartilhavam suas vidas, o que proporcionou sentimentos de solidão e perda.

O medo foi um sentimento bastante expresso pelas cuidadoras filhas e esposas dos idosos com Alzheimer. 0 medo de ficar doente também, da dependência total do idoso e da evolução da doença se fizeram presentes nos discursos das cuidadoras. Segundo Santana (2003), a situação de cuidar do idoso com demência pode provocar o sentimento de compaixão, o medo da morte e da dependência por parte do cuidador, o que torna a situação do mesmo ainda mais delicada frente ao cotidiano do cuidado.

A compaixão é um sentimento que aparece também neste estudo, em que o cuidador sofre pelo sofrimento do idoso doente. Resende e colaboradores (2008) em seu estudo também identificam que dentre os sentimentos envolvidos no processo de cuidar, aquele que mais aflige as cuidadoras é o de ver o sofrimento e a tristeza do idoso sob cuidado.

A solidão foi uma marca registrada no momento de cuidado expressa nos depoimentos das esposas cuidadoras de seus maridos, principalmente daquelas que vivenciaram um casamento repleto de companheirismo e amor. Essas idosas se sentem sozinhas diante da situação imposta pela Doença de Alzheimer em seu marido. Sentimento este que também foi encontrado no estudo de Braz (2008) com cuidadores senescentes de idosos dependentes.

Para Liger (1994), a solidão é o sentimento de ser cortado dos outros. As cuidadoras idosas deste estudo se sentem cortadas da vida dos seus companheiros, em função da instalação da perda da memória ou a iminência desta inerente à Doença de Alzheimer. Barreto (1992, p. 32), consegue explicar melhor a vivência de solidão dessas cuidadoras quando diz que:

[...] o sentimento de solidão geralmente ocorre quando se procura companhia de alguém e não se acha, quando as palavras não encontram um ouvido para escutá-las e se deterioram, quando a dor, a saudade, a mágo a tornam-se muito pesadas por falta de um ombro amigo, e a alegria não se atualiza em um rir junto [...].

Assim pode-se dizer que a solidão é um estado emocional marcado pela carência de relacionamentos afetivos importantes e calorosos (Vargas, 1997). Relacionamentos estes construídos ao longo da história matrimonial das cuidadoras idosas deste estudo, que cuidam de seus maridos, e que em função da doença foram interrompidos pela alteração da memória.

Os estudos de Creutzberg e Santos (2003) e Karsh (2006) enfatizam que as estruturas de suporte social no Brasil ainda se mostram frágeis e não se constituem uma rede de apoio organizada, demonstrando a insuficiência de políticas sociais que proporcionem suporte às famílias cuidadoras de idosos fragilizados.

\section{Considerações Finais}

Os resultados mostram que os cuidadores deste estudo vivenciam momentos de impaciência, gerados pela dificuldade de conduzir e gerenciar uma dada situação em tempo hábil no contexto do cuidado, que logo se transformam em sentimentos de culpa. Estes familiares comumente não têm condições de potencializar seus próprios mecanismos protetores de combate à exaustão. Estes cuidadores, ao se referirem constantemente à necessidade de "paciência", expressam a dificuldade de manter o autocontrole no processo do cuidado. A solicitação e a cobrança dos profissionais para que os cuidadores sejam pacientes em seu dia a dia causam uma reação de revolta nestes. É preciso que os profissionais, sobretudo o enfermeiro, percebam as necessidades de ajuda sinalizadas pelos cuidadores, sem, contudo rotular um padrão de comportamento e reação que estes devam seguir.

É importante salientar que neste estudo, a situação de cuidado vivenciada pelos cuidadores é permeada por sentimentos que se contrapõem, em determinados momentos se configurando como desagradáveis e em outros momentos como agradáveis. Tal dualidade nos remete a perceber que aqui o cuidador é um ser que vivencia diversos tipos de reações, frente à situação de cuidado do seu ente querido e que nem sempre são totalmente ruins. Diante de inúmeras dificuldades inerentes ao cotidiano de execução das tarefas, há também sentimentos que lhes trazem satisfação e que precisam de ser considerados e valorizados em suas várias dimensões, apesar da situação de cuidado requerer um grande dispêndio de energia que muitas vezes se torna bastante cansativo. Sendo assim, percebe-se que é 
possível e relevante os profissionais da saúde identificarem esses aspectos favorecedores de prazer na relação de cuidado, buscando exaltá-los perante os outros. Dessa forma, a possibilidade de enfrentar da melhor forma os percalços deve ser considerada uma realidade eminentemente presente no cotidiano de cuidado.

Nesta perspectiva, é preciso desconstruir o conceito de que a situação de cuidado do familiar idoso com a doença de Alzheimer só traz danos, sem chances de reversão. É necessário que o imutável daquilo que acreditamos ser, enquanto profissionais da saúde, se exclua das nossas atitudes e assim possamos observar as perdas como favorecedoras de renovação e reelaboração da forma de ver o mundo e os outros, para que diante de uma nova realidade, muitas vezes, não desejável, a valorização das estratégias de enfrentamento que o cuidador possui seja bem mais significativa.

\section{Referências}

ALMBERG, B.; GRAFSTROM, M.; WENBLAD, B. Caring for a demented elderly person: burden and burnout among caregivining relatives. Journal of Advanced Nursing, Oxford, v. 25, n. 1, p. 109-116, 1997.

ALVAREZ, A. M. Tendo que cuidar: a vivencia do idoso e de sua família no processo de cuidar e ser cuidado em contexto familiar. Florianópolis: UFSC, 2001.

ANDRÉ, M. O qualitativo e o quantitativo: oposição ou convergência? In: REUNIÃo ANUAL DE PSICOLOGIA, 18., 1988, Ribeirão Preto. Anais... Ribeirão Preto: SPRP, 1988. p. 18.

BARRETO, M. L. Admirável mundo velho: velhice, fantasia e realidade social. São Paulo: Ática, 1992.

BIASOLI-ALVES, Z. M.; DIAS DA SILVA, M. H. G. F. Análise qualitativa de dados de entrevista: uma proposta. Paidéia, Ribeirão Preto, v. 1, n. 2, p.61-9, 1992.

BIASOLI-ALVES, Z. M. M. Família- socializaçãodesenvolvimento. 1995. 132 f. Tese (Livre-Docência) - Faculdade de Filosofia Ciências e Letras de Ribeirão Preto, Universidade de São Paulo, Ribeirão Preto.
BRAZ, E. Entre o visivel e o invisivel: as representações sociais no cotidiano do senescente cuidador de idosos dependentes. 2008. $158 \mathrm{f}$. Tese (Doutorado em Enfermagem) - Escola de Enfermagem, Universidade de São Paulo, São Paulo.

CALDANA, R. H. L. Ser criança no início do século: alguns relatos e suas lições. 1998. 188 f. Tese (Doutorado em Psicologia) - Centro de Educação e Ciências Humanas, Universidade Federal de São Carlos, São Carlos.

CALDEIRA, A. P. S.; RIBEIRO, R. C. H. M. O enfrentamento do cuidador do idoso com Alzheimer. Arquivos de Ciências da Saúde, São José do Rio Preto, v. 11, n. 2, p. 100-4, abr./jun. 2004.

CREUTZBERG, M.; SANTOS, B. R. L. Família cuidadora de pessoa idosa: relação com instituições sociais e de saúde. Revista Brasileira de Enfermagem, Brasilia, v. 56, v. 6, p.651-4, 2003.

GOLDFARB, D. C. Autoestima e dignidade. Comunicação com o cuidador. Revista Brasileira de Enfermagem, Brasília, v. 1, n. o, p. 3-3, 1996.

KARSCH, U. M. Idosos dependentes: familiares e cuidadores. In: KARSCH, U. M. (Org.). Envelhecimento com dependência: revelando cuidadores. Rio de Janeiro: Guanabara, 2006. p. 67-74.

KRAMER, B. J. Gain in the caregiving experience: where are we? What next? The Gerontologist, New York, v. 37, n. 2, p. 218-32, 1997.

LIGER, J. M. et al. Psicologia do envelhecimento: assistência aos idosos. Rio de Janeiro: Vozes, 1994. LUZARDO, A. R.; GORINI, M. I. P. C.; SILVA, A. P. S. Características de idosos com demência de Alzheimer e seus cuidadores: uma série de casos em um serviço de neurogeriatria. Texto e Contexto: Enfermagem, Florianópolis, v. 15, n. 4, p. 587-94, out./dez. 2006.

MAZZA, M. M. P. R.; LEFÈVRE F. Cuidar em família: análise da representação social da relação do cuidador familiar com o idoso. Revista Brasileira de Crescimento e Desenvolvimento Humano, São Paulo, v. 15, n. 1, p. 01-10, 2005. 
MEIRA, E. C.; GONÇALVES, L. H. T.; XAVIER, J. O. Relatos orais de cuidadores de idosos doentes e fragilizados acerca dos fatores de risco para violência intrafamiliar. Ciência, Cuidado e Saúde, Maringá, v. 6, n. 2, p. 171-8o, abr./jun. 2007.

NARDI, E. F. R.; OLIVEIRA, M. L. F. Conhecendo o apoio social ao cuidador familiar do idoso dependente. Revista Gaúcha de Enfermagem, Porto Alegre, v. 29, n. 1, p. 47-53, mar. 2008.

NÉRI, A. L.; CARVALHO, V. A. M. O bem-estar do cuidador: aspectos psicossociais. In: FREITAS, E. V. et al. Tratado de geriatria e gerontologia. Rio de Janeiro: Guanabara Kogan, 2002. p. 778-9o.

NOONAN, A. E.; TENNSTEDT, S.L. Meaning in caregiving and its contribution to caregiver wellbeing. The Gerontologist, New York, v. 37, n. 6, p. 295-308, 1997.

OLIVEIRA, A. P. P. O cuidado familiar na perspectiva de cuidadores de idosos com demência de Alzheimer. 2009. Tese (Doutorado em Psicologia) - Faculdade de Filosofia, Ciências e Letras da Universidade de São Paulo, Ribeirão Preto, SP.

PAVARINI, S. C. I. et al. Cuidando de idosos com demência: a vivência de cuidadores familiares. Revista Eletrônica de Enfermagem, Goiania, v10, n. 3, 2008. Disponível em: <http://www.fen.ufg.br/ revista/v1o/n3/pdf/v1onzao4.pdf>. Acesso em: 26 set. 2009.

PEGORARO, R. F. Receber e prover cuidados: a trajetória de uma mulher em sofrimento psiquiátrico. 2007. Tese (Doutorado em Psicologia) - Faculdade de Filosofia Ciências e Letras de Ribeirão Preto, Universidade de São Paulo, Ribeirão Preto.

PERRACINI, M. R.; NÉRI, A. L. Tarefas de cuidar: com a palavra, mulheres cuidadoras de idosos de alta dependência. In: NERI, A. L. (Org.). Cuidar de idosos no contexto da família: questões psicológicas e sociais. 2 ed. Campinas: Alínea, 2006. p. 165-201.

RESENDE, M. C. et al. Cuidar de idosos com Alzheimer: influências sociais, físicas e psicológicas envolvidas nesta tarefa. RBCEH, Passo Fundo, v. 5, n. 1, p.19-31, jan./jun. 2008.
SANTANA, R. F. Grupo de orientação em cuidados na demência: relato de experiência de uma enfermeira aluna do curso de psicogeriatria. Textos sobre Envelhecimento, Rio de Janeiro, v. 5, n. 9, p.1-5, 2003.

SANTOS, S. M. A. Idosos, família e cultura: um estudo sobre a construção do papel do cuidador. Campinas: Alínea, 2003.

SOMMERHALDER, C. Significados associados à tarefa de cuidar de idosos de alta dependência no contexto familiar. 2001. 86 f. Dissertação (Mestrado em Gerontologia) - Faculdade de Educação, Universidade Estadual de Campinas, Campinas.

SOMMERHALDER, C.; NÉRI, A. L. Avaliação subjetiva da tarefa de cuidar: ônus e benefícios percebidos por cuidadoras familiares de idosos de alta dependência. In: NÉRI, A. L. (Org.). Cuidar de idosos no contexto da família: questões psicológicas e sociais. Campinas: Alínea, 2002. p. 93-134.

TEIXEIRA, M. H. Relação interpessoal: cuidadoridoso dependente/cuidador família. In: CALDAS, C. P. A saúde do idoso: a arte de cuidar. Rio de Janeiro: Eduerj, 1998. p. 139-41.

TOZO, S. M. P. S. O ciclo de vida familiar: um estudo transgeracional. 2002. Tese (Doutorado em Psicologia) - Faculdade de Filosofia Ciencias e Letras, Universidade de São Paulo, Ribeirão Preto, SP.

VARGAS, H. S. A sociologia do envelhecimento. In: Universidade do Estado do Rio de Janeiro. Universidade aberta da terceira idade. $2^{a}$ curso de formação de cuidadores de idosos dependentes. Rio de Janeiro: UERJ, 1997. p.6-12

VIEIRA, E. B. Manual de gerontologia: um guia prático para profissionais, cuidadores e familiares. 2. ed. Rio de Janeiro: Revinter, 2004.

Recebido em: 27/11/2010

Reapresentado em: 08/11/2011

Aprovado em: 23/01/2012 